\title{
Probiotic supplement and gluten withdrawal in gluten allergy Patients may lead to gluten tolerance: first case report
}

\author{
Moni Kumari ${ }^{1,2}$, Renu Bansal ${ }^{3}$, Shifali Gupta ${ }^{4}$, Ranjit Singh ${ }^{2}$, Praveen Bansal ${ }^{5}$, Malika Arora $^{1 *}$
}

\author{
${ }^{1}$ Multidisciplinary Research Unit, ${ }^{4}$ Department of Paediatrics, Guru Gobind Singh Medical College and Hospital, \\ Faridkot, Punjab, India \\ ${ }^{2}$ Adarsh Vijendra Institute of Pharmaceutical Sciences, Saharanpur, Uttar Pradesh, India \\ ${ }^{3}$ Department of Microbiology, Government Medical College, Patiala, Punjab, India \\ ${ }^{5}$ University Center of Excellence in Research, Baba Farid University of Health Sciences, Faridkot, Punjab, India
}

Received: 23 May 2021

Accepted: 16 June 2021

\section{*Correspondence:}

Dr. Malika Arora,

E-mail: maliksmonu@gmail.com

Copyright: (C) the author(s), publisher and licensee Medip Academy. This is an open-access article distributed under the terms of the Creative Commons Attribution Non-Commercial License, which permits unrestricted non-commercial use, distribution, and reproduction in any medium, provided the original work is properly cited.

\begin{abstract}
Probiotic species such as lactobacillus and bifidobacteria are known to have a major role in gluten digestion and regulation of proper functioning of gastrointestinal system however these are found to be missing in gluten allergy patients. So, here in this case we aimed to find the effect of probiotic supplementation along with gluten free diet in celiac disease patient. A case of an 8-year-old female child admitted to civil hospital, Faridkot with chief complaints of vomiting, diarrhea, weight loss, retarded growth, and malnutrition was studied. When she first visited the hospital, based on her symptoms, she was advised celiac disease workup and was found to be highly tTG IgA positive (10.62). The subject was shifted to a strict gluten free diet along with probiotic supplementation. The subject was regularly followed up for the period of four and half years in order to find improvement in her symptoms. After 4 years, gluten diet was gradually reintroduced in a phased manner; the patient remained well even on full gluten diet. This may be due to probiotic supplementation to the subject along with gluten free diet. Present case report describes the spontaneous recovery of celiac disease patient after strict adherence to gluten free diet and probiotic supplementation for a specified period. It is suggested that there should be a proper monitoring and detailed evaluation of clinical and histological markers of recovery in a patient after strict adherence to gluten free diet and probiotic supplementation in order to evaluate the possible role of probiotic supplements in the management of CD.
\end{abstract}

Keywords: Celiac disease, Probiotic supplements, Gluten free diet

\section{INTRODUCTION}

Celiac disease $(\mathrm{CD})$ is gluten mediated autoimmune systemic disorder, presenting in individuals genetically predisposed to HLA-DQ2 and HLA-DQ8 haplotypes. The disease is characterized by inflammation in intestinal mucosa and villous atrophy of small bowel, leading to symptoms of mal-absorption such as weight loss, diarrhea, or other signs of vitamin or nutrient deficiency. ${ }^{1}$ Traditionally the disease is diagnosed by serological testing along with confirmatory examination with biopsy, however recent 2020 ESPGHAN guideline suggest "nobiopsy approach for CD diagnosis, is confirmed to be safe in children with high TGA-IgA values $\geq 10$ times the upper limit of normal. Children with positive TGA-IgA but lower titers ( $<10$ times upper limit of normal) should undergo biopsies to decrease the risk of false positive diagnosis". Serological testing is being preferred by many clinicians due to its easy availability and reliability. Till date the only available treatment for $\mathrm{CD}$ is lifelong adherence to gluten free diet. ${ }^{2}$ 
The gut microbiota is the aggregation of various microorganisms that resides within the human digestive system. It is supposed to play a most important role in a number of diseases. Microbiota plays a crucial role in the maturation of the immune system, being essential for the development of tolerogenic/protective immune responses. Current evidences show that environmental agents and/or endogenous signals may cause dysbiosis, which is responsible for a breakdown of immune homeostasis and an increase in the risk of immune conditions such as CD, among others. In $\mathrm{CD}$, the composition of gut microbiota gets altered compared with healthy controls and thus has been hypothesized to contribute to its pathology. ${ }^{3}$ In particular, studies have found decrease in beneficial bacteria such as Lactobacillus and Bifidobacterium in intestinal microbiota/faecal microbiota of untreated patients with $\mathrm{CD}$, which suggests that regulation of the gut microbiota, by administration of probiotics, may be an emerging adjuvant therapy in CD. ${ }^{4}$ In various studies, some probiotics shown to have anti-inflammatory properties, and therefore, they may possibly attenuate gluten-induced inflammation in patients with CD. ${ }^{5}$ In this case study, we present the case of a 8-year-old girl child who was having gluten allergy/CD. The role of GFD along with probiotic supplementation has been mainly highlighted in the study along with the need of proper diagnosis and timely follow-up of the patient.

\section{CASE REPORT}

A 8-year-old female child, a resident of urban area of Faridkot presented to the outpatient department in pediatrics unit of Civil Hospital, Faridkot with chief complaint of vomiting, diarrhea, weight loss, growth retardation and malnutrition. She also had symptoms of hyper reactive airway disease and skin allergy. Her parents were interviewed in detail; it was found that she had history of altered bowel habits, easy fatigue ability as compared to peers, decreased exercise intolerance, poor concentration, poor weight gain, recurrent cough cold while seasonal changes, and allergic dermatitis. Routine investigations like hemogram were suggestive of microcytic hypochromic anemia, with normal renal and liver function tests. Keeping strong suspicion of celiac disease in mind, tTG IgA was ordered, which came well above reference normal range which indicated the patient to be celiac positive. Biopsy was also suggested but patient's parents denied for the same. As tTG IgA value for the patient was very high, so biopsy was not forced. Patient was shifted to strict gluten free diet after counseling. Along with gluten free diet she was advised to have probiotic supplements. She remained on gluten free diet and probiotic supplements completely for a period of 3 years. The patient was routinely followed up once in a month during this period for her symptoms review, growth and full physical examination. Her symptoms started to improve in next few months. She gained $11 \mathrm{~kg}$ weight in 4 years and height increased from $130 \mathrm{~cm}$ to $150 \mathrm{~cm}$. Later on she was advised to reintroduce gluten containing diet once in a week initially followed by thrice a week. To our surprise she did not have any GI symptoms this time and repeat TTG report was negative. Later the subject switched to gluten diet and her symptoms of Gluten allergy/CD completely disappeared. She was counseled regarding any other symptoms or difficulty and was advised to consult the doctor as soon as any symptom reappears. The details of patient before and after treatment are mentioned in Table 1.

Table 1: The details of patient before and after treatment.

\begin{tabular}{|lllll} 
Treatment Stage & tTG-IGA & Gluten & $\begin{array}{l}\text { Presence of Microbiota in } \\
\text { fecal samples }\end{array}$ & $\begin{array}{l}\text { Clinical Symptoms } \\
\text { Before treatment }\end{array}$ \\
$\begin{array}{llll}\text { Highly } \\
\text { positive } \\
(10.62)\end{array}$ & Intolerance & $\begin{array}{l}\text { Pathogenic microbes were in } \\
\text { abundance and absence of } \\
\text { probiotic microbiota in fecal } \\
\text { sample of patient. }\end{array}$ & $\begin{array}{l}\text { Vomiting, diarrhea, weight loss, } \\
\text { growth retardation, malnutrition, } \\
\text { hyper reactive airway disease } \\
\text { and skin allergy }\end{array}$ \\
After treatment & $\begin{array}{l}\text { Negative } \\
(0.74)\end{array}$ & Tolerance & $\begin{array}{l}\text { Reappearance of probiotic } \\
\text { microbiota in fecal sample of } \\
\text { the patient. }\end{array}$ & $\begin{array}{l}\text { Celiac disease symptoms } \\
\text { disappeared, and the patient } \\
\text { gained weight. Her height also } \\
\text { increased. }\end{array}$ \\
\hline
\end{tabular}

\section{DISCUSSION}

Earlier it was a hypothesis that gluten free diet is the one and only treatment for celiac disease and gluten allergy and the patient needs to adhere on gluten free diet for lifetime but now there is evidence which proves that gluten free diet along with co-administration of probiotic supplements can reverse the situation. Probiotics are well known to help in digestion of gluten and also there are various evidences which proves that probiotics reverses the inflammatory disturbances created by gluten within small intestine. ${ }^{5}$ There are few case reports published reporting the benefits of gluten free diet along with probiotics in celiac disease. For most of the CD patients, gluten free diet stops symptoms, heals the existing intestinal damage, and prevents further damage6. Now the exact reason for the same is still unknown. In this case study, the patient was advised to take probiotic 
supplements regularly along with GFD. Probiotic supplementation may be a probable reason for recovery from CD. There is no such case study till date which reports complete recovery of patient from celiac disease after administration of probiotic supplements along with GFD, but there are studies which indicate the positive prospects of probiotics in CD. ${ }^{7-9}$ Primec et al in 2018 performed a double-blind placebo-controlled trial on 40 $\mathrm{CD}$ and 16 healthy children. CD patients were randomized to receive a mixture of two Bifidobacterium breve strains (DSM 16604 and DSM 24706) or placebo for a period of three months. The researchers observed that this probiotic mixture was able to enhance the production of acetic acid and total short-chain fatty acids (SCFAs), promoting a potential role in microbiome restoration. ${ }^{9}$

\section{Probable mechanism of action of probiotics}

Probiotics are the major components of healthy microbiota and shown to have beneficial role in case of CD. Probiotics can have influence on the pathogenesis of $\mathrm{CD} /$ Gluten allergy by decreasing the permeability of intestine through altering zonulin release and tight junction expression. Supplementation of probiotics to CD patient can modulate the presence of probiotics in gut microbiota and thus helps CD patients in attaining a healthy microbiota. The undigested gliadin peptides lead to autoimmune activity by the immune system and thus damage the villi. Probiotics amend gluten peptides digestion and thus regulate immune system activity via generation of anti-inflammatory cytokines such as IL 10, IL 11 and thus helps in restoration of healthy intestine. ${ }^{10}$ The probable mechanism of action of probiotics has been shown in Figure 1.

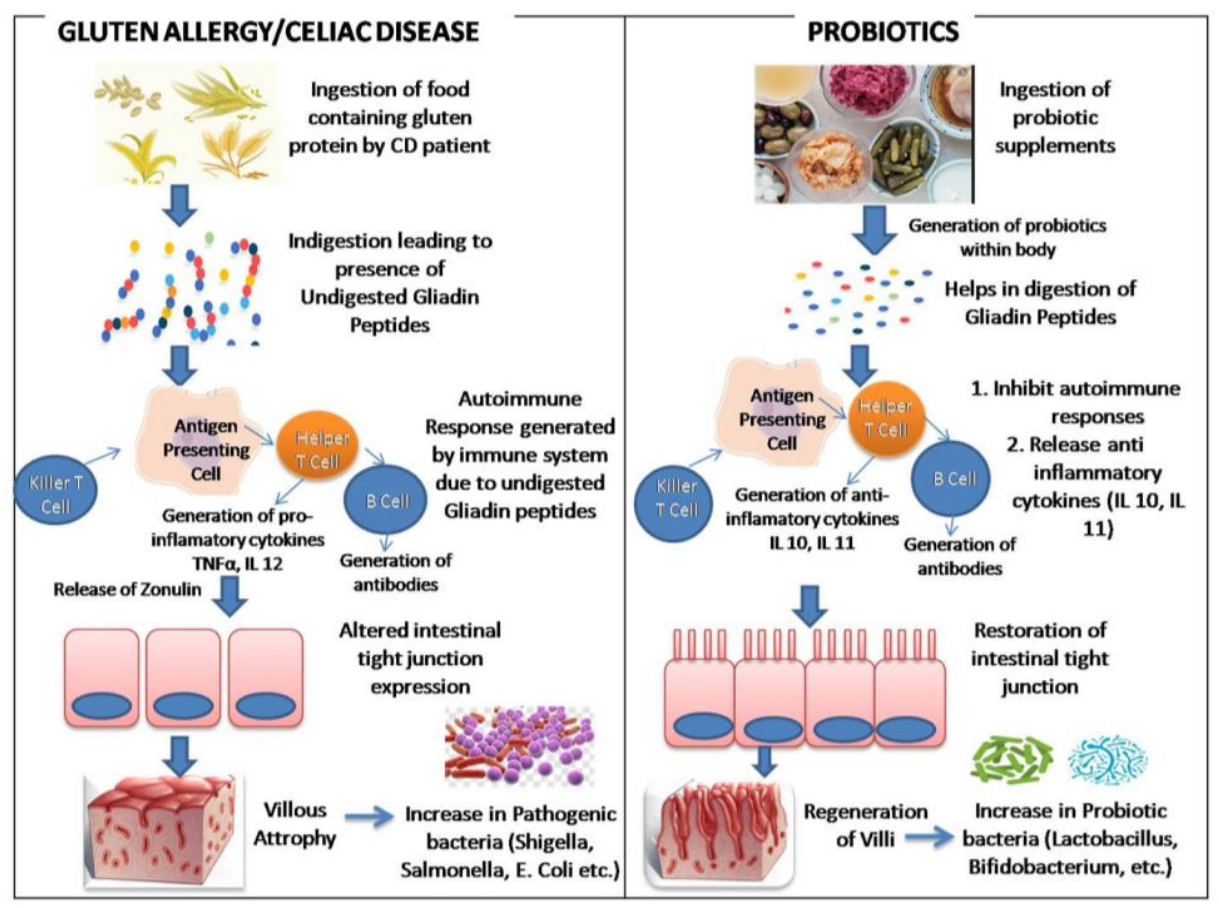

Figure 1: Probable mechanism of action of probiotics.

\section{CONCLUSION}

The present case report describes that Probiotic supplementation along with strict adherence to gluten free diet might help gluten allergy/CD patients in developing tolerance to gluten diet and improve the quality of life of patients in their eary age. Also, detailed evaluation of clinical as well as histological markers of recovery in a patient after strict adherence to gluten free diet and probiotic supplementation is recommended in order to evaluate the possible role of probiotic supplements in management of CD. Hence there is a need for routine follow up, to assess patient compliance and response to prescribed treatment strategy. There is also a strong need of educating patients and their caregivers about the effectiveness of strict adherence to the treatment suggested, so that any adverse effect can be recognized early and treated appropriately.

\section{ACKNOWLEDGEMENTS}

The authors acknowledge Department of Pediatrics, Dr. Rajinder and Civil Hospital, Faridkot for sharing the information.

Funding: This research was funded by a grant from DSTSYST Project No. SP/YO/097/2017

Conflict of interest: None declared

Ethical approval: Not required 


\section{REFERENCES}

1. Pelkowski TD, Viera AJ. Celiac disease: diagnosis and management. Am Fam Physician. 2014;89:99105.

2. Gładyś K, Dardzińska J, Guzek M, Adrych K, Małgorzewicz S. Celiac dietary adherence test and standardized dietician evaluation in assessment of adherence to a gluten-free diet in patients with celiac disease. Nutrients. 2020;12:2300.

3. Verdu EF, Galipeau HJ, Jabri B. Novel players in coeliac disease pathogenesis: role of the gut microbiota. Nat Rev Gastroenterol Hepatol. 2015;12:497-500.

4. Nistal E, Caminero A, Vivas S, de Morales JM, de Miera LE, Rodríguez-Aparicio LB, et al. Differences in faecal bacteria populations and faecal bacteria metabolism in healthy adults and celiac disease patients. Biochimie. 2012;94:1724-9.

5. Francavilla R, Cristofori F, Vacca M, Barone M, De Angelis M. Advances in understanding the potential therapeutic applications of gut microbiota and probiotic mediated therapies in celiac disease. Expert Rev Gastroenterol Hepatol. 2020;28:1-1.

6. Gayathri D, Ramesha A. Gluten hydrolyzing probiotics: An emerging therapy for patients with celiac disease. World Acad Sci J. 2020;2:1.
7. Marasco G, Di Biase AR, Schiumerini R, Eusebi LH, Iughetti L, Ravaioli F, et al. Gut microbiota and celiac disease. Dig Dis Sci. 2016;61:1461-72.

8. Seiler CL, Kiflen M, Stefanolo JP, Bai J, Bercik P, Kelly C, et al. Probiotics for Celiac Disease: A Systematic Review and Meta-Analysis of Randomized Controlled Trials. Am J Gastroenterol. 2020;115:1584-95.

9. Primec M, Klemenak M, Di Gioia D, Aloisio I, Cionci NB, Quagliariello A, et al. Clinical intervention using Bifidobacterium strains in celiac disease children reveals novel microbial modulators of TNF- $\alpha$ and short-chain fatty acids. Clin Nutr. 2019;38:1373-81.

10. Norouzbeigi S, Vahid-Dastjerdi L, Yekta R, Sohrabvandi S, Zendeboodi F, Mortazavian AM. Celiac therapy by administration of probiotics in food products: a review. Curr Opin Food Sci. 2020;32:58-6

Cite this article as: Kumari M, Bansal R, Gupta S, Singh R, Bansal P, Arora M. Probiotic supplement and gluten withdrawal in gluten allergy Patients may lead to gluten tolerance: first case report. Int J Community Med Public Health 2021;8:3603-6. 